\title{
ATYPICAL SUBACUTE SCLEROSING PANENCEPHALITIS
}

\section{Case report}

\author{
Marcelo Maroco Cruzeiro', Thiago Cardoso Vale?2, \\ Leopoldo Antônio Pires 3 , Gláucio Mendes Franco ${ }^{4}$
}

\begin{abstract}
Subacute sclerosing panencephalitis (SSPE) is a progressive inflammatory disorder of the central nervous system with both poor prognosis and high mortality. The disease has been related to a persistent and aberrant measles virus infection and no effective treatment has been available. We report a case of SSPE with atypical features including seizures at onset and a fulminant course in a 8 years-old boy who had been previously immunized against measles.
\end{abstract}

KEY WORDS: subacute sclerosing panencephalitis, measles, immunization.

\begin{abstract}
Panencefalite esclerosante subaguda: relato de caso atípico
RESUMO - Panencefalite esclerosante subaguda (PES) é uma doença inflamatória e progressiva do sistema nervoso central com prognóstico reservado e alta mortalidade. A doença tem sido relacionada com a infecção persistente e anormal pelo vírus do sarampo e não há tratamento específico disponível. Relatamos um caso de PES com características atípicas representadas por início do quadro com crises convulsivas e apresentação fulminante em menino de 8 anos previamente imunizado contra o vírus do sarampo.
\end{abstract}

PALAVRAS-CHAVE: panencefalite esclerosante subaguda, sarampo, imunização.

Subacute sclerosing panencephalitis (SSPE) is a progressive inflammatory disorder of the central nervous system (CNS) related to a persistent and aberrant measles virus infection. It occurs in an incidence of 1 per 100,000 to 500,000 measles cases, usually affecting people aged 10 to 14 years $^{1,2}$. The annual incidence of SSPE in both adults and children after measles infection dropped from 1 per 100,000 in the preimmunization era to 0.06 per 100,000 after immunization was implemented ${ }^{2}$. In developing countries, an incidence as high as 20-100 per 100,000 has been reported $^{2}$. The incidence is higher in males with a ratio of 2-4:1 female 3 . In Brazil, there are few reports available, except for the study of Nunes et al. ${ }^{4}$, in the end of the nineties, showing endemic regions in the country and a delay between first symptoms and diagnosis. In India, the incidence rate is very high (21 per mil- lion population) and linked to the high frequency of cases of measles among the very young ${ }^{5}$. In the classic form of SSPE, slow progression of neurological symptoms goes through four characteristic stages ${ }^{6,7}$. SSPE is slowly progressive with death occurring within three years. Up to $10 \%$ of cases show a different clinical picture with a fulminant or prolonged course ${ }^{5}$. Typical neurological manifestations include progressive intellectual deterioration, psychomotor impairment, myoclonic jerks and behavioural changes, with or without pyramidal and extrapyramidal symptoms 8 .

We report the case of an 8-year-old boy presenting with atypical SSPE diagnosed through the clinical picture, electroencephalogram (EEG) and cerebrospinal fluid (CSF) analysis, after other diagnoses were excluded. The aim of this report is to emphasize the importance of considering a different clinical presenta-

\footnotetext{
'Neurology Service, Department of Internal Medicine at University Hospital of Federal University of Juiz de Fora, Juiz de Fora MG, Brazil: 'MD, MSc in Neurology, Fluminense Federal University (UFF), Niterói RJ, Brazil, Neurologist and neurophysiologist. Assistant lecturer in the Neurology Service, Department of Internal Medicine at University Hospital of Federal University of Juiz de Fora, Juiz de Fora MG, Brazil; ${ }^{2}$ Undergraduate trainee in the Neurology Service, Department of Internal Medicine at University Hospital of Federal University of Juiz de Fora, Medical student at Federal University of Juiz de Fora, Juiz de Fora MG, Brazil; ${ }^{3} \mathrm{MD}$, MSc in Neurology, São Paulo Federal University, São Paulo SP, Brazil (UNIFESP), Neurologist, Lecturer and head of the Neurology Service, Department of Internal Medicine at University Hospital of Federal University of Juiz de Fora, Juiz de Fora MG, Brazil; ${ }^{4} \mathrm{MD}$, Doctor in Neurology, UFF, MSc in Neurology, Rio de Janeiro Federal University, Rio de Janeiro SP, Brazil, Neurologist and Neurophysiologist, Former Head of the Neurology Service and Senior Lecturer in the Neurology Service, Department of Internal Medicine at University Hospital of Federal University of Juiz de Fora, Juiz de Fora MG, Brazil.
}

Received 13 April 2007, received in final form 18 July 2007. Accepted 27 August 2007.

Dr. Marcelo Maroco Cruzeiro - Avenida Rio Branco 2370 / 802 - 36010-011 Juiz de Fora MG - Brasil. E-mail: mmaroco@terra.com.br 
tion of SSPE and its ocorrence in previously immunized subjects, particularly among the pediatric population.

\section{CASE}

A formely healthy 8-year-old boy presented at the neurology service with a two-month history of behavioural disturbances, mainly manifested by emotional lability and apathy associated with impairment of educational performance. This clinical picture was followed by complex partial seizures with secondary generalization, with normal interictal EEG and cranial computed tomography (CT). Despite having been treated with gamma-aminobutyric acid, the patient's condition worsened progressively in the following two months, with amnesia, worsening of behavioural pattern, speech and cognitive impairment. He was hospitalized for further investigations. The patient did not have any prior history of measles infection, his immunization history was normal, including vaccination against measles when he was ten months and five years old. His developmental milestones were normal and there was no family background of neurological disorders.

Carbamazepine was prescribed due to the onset of generalized myoclonic movements and tonic seizures. Recurrent seizures led to the prescription of valproic acid combined with clonazepam. Another EEG showed generalized periodic high-amplitude sharp waves. CSF analysis showed pleocytosis (29 leukocytes $/ \mathrm{mm}^{3}$ with $69 \%$ neutrophils, $10 \%$ lymphocytes and $21 \%$ monocytes) and elevated protein (115 $\mathrm{mg} / \mathrm{dL}$ ) and globulin levels ( $35 \mathrm{mg} / \mathrm{dL}$ ). The measles immunoglobulin G titer was over 1:200 on CSF analysis and it was greater than the serum titer (1:80). Polymerase chain reaction for Herpes simplex virus (HSV) was negative as well as serum and CSF Varicella zoster virus (VZV) serology.

The patient became nonverbal and developed trism and an irregular respiratory pattern. Physical examination revealed a lethargic boy with increased muscular tone, diffuse rigidity, semi-opisthotonous position, mutism and decerebration. During his stay in hospital, a respiratory infection led to unsuccessful antibiotic treatment. He died after two months in hospital and after six months of symptom onset.

This case report was written with the approval of the Ethics Committee of the University Hospital of the Federal University of Juiz de Fora (Minas Gerais), Brazil.

\section{DISCUSSION}

At least three of the following five criteria should be met for SSPE diagnosis',2: a) a typical clinical picture of progressive subacute mental deterioration with typical signs like myoclonus and neurodiagnostic features consistent with SSPE; b) characteristic EEG changes; C) CSF globulin levels greater than $20 \%$ of total CSF protein; d) raised titers of measles antibodies in blood and CSF in the absence of other antibodies, including against HSV and VZV and d) typical histopathological findings on brain biopsy or autopsy.

There are several major theories regarding the pathogenesis of SSPE. The chronicity of the measles vi- rus infection, the early acquisition of measles infection when the immune system is immature, and the onset of clinical disease long after the primary infection all suggest an abnormal host immune response with an inability to clear the viral infection ${ }^{5.9}$. In addition to an abnormal host response, there may be immune modulation of the intracellular expression of the measles virus-encoded proteins. In early acquisition of measles infection, circulating maternal antibody levels may not be sufficient to be protective, but may still modulate the virus. Anti-measles antibody produced in response to infection may also modulate the virus to decrease measles antigen expression. The virus could then evade immune recognition, and the acute infection would be able to convert to a chronic persistent infection ${ }^{5}$. Decreased recognition by the immune system may also be achieved by the development of a mutant virus generated during acute infection.

Most patients with SSPE have a history of primary measles infection at an early age ( $<2$ years), followed by a latent period of 6-8 years ${ }^{10}$. The risk of developing SSPE is higher when measles occurs during the first 2 years of life, which suggests that immune immaturity plays an important role in the pathogenesis of the disease'. Widespread immunization has produced greater than $90 \%$ reduction in the incidence of SSPE in developed nations ${ }^{10}$. Nevertheless, measles outbreaks still occur in countries that have not reached comprehensive immunization schedules for their whole population. Approximately, 45 million cases of measles, with nearly 800,000 fatalities, occur annually according to the World Health Organization". In underdeveloped countries, the rates of SSPE may be high due to higher levels of circulating wild type virus and infection of immunized individuals.

When the disease occurs in immunized children, as in our patient, it is thought to result from a subclinical measles infection that occurred before 1 year of age, when immunization usually begins. The typical clinical picture of measles may have been altered by the presence of maternal antibodies. It has also been speculated that the infection in this circumstance may be due to infection by a wild strain which is not included in the vaccine used ${ }^{12}$. There is no evidence to suggest that the attenuated vaccine virus is responsible for sporadic cases of SSPE${ }^{8}$. This issue definitely requires a wider epidemiological survey before one can conclude that there is a direct relationship between measles vaccination and subsequent SSPE.

In a series of 48 patients, Nunes et al. ${ }^{4}$ reported seven cases $(14 \%)$ of SSPE in previously immunized patients. In the Canadian Paediatric Surveillance Pro- 
gram, Campbell et al.7 diagnosed four cases of SSPE, of whom one was previously immunized (25\%) and presented with an atypical EEG pattern. Salehi et al. ${ }^{8}$ reported three atypical cases of SSPE in immunized patients. In a large study conducted in India ${ }^{13}, 307$ SSPE patients were included and nineteen (6.2\%) presented with atypical features including seizures as initial manifestation. Of those patients, two developed SSPE despite being previously immunized. Forty-two cases of SSPE were diagnosed in Wales and England between 1990 and 2002. Four children with a history of receipt of a measles containing vaccine were reported not to have had measles; two of these cases had a brain biopsy, and nucleotide sequence data confirmed wild measles infection. Brain biopsy specimens from a further three cases with a history of measles, of whom two had also had a history of vaccination, showed wild-type strain ${ }^{14}$. Bojinova et al. ${ }^{15}$ conducted a 25-year-epidemiological study in Bulgaria, where forty children presented with SSPE. Nine (22.5\%) presented with atypical features, four (10\%) with a fulminant course and two ( $5 \%$ ) developed SSPE despite being previously immunized. In South China, Ip et al. ${ }^{16}$ diagnosed ten cases of SSPE, of whom three (30\%) were previously immunized. In Eastern Highlands of Papua Guinea, Takasu et al. ${ }^{17}$ diagnosed SSPE in 55 patients, of whom eleven (20\%) developed SSPE after immunization against measles.

Our patient presented behavioural disturbances, mainly manifested by emotional lability and apathy, shortly followed by seizures, regarded as an uncommon initial symptom of SSPE. He had seizures in the first Jabbour ${ }^{6}$ stage and the second one lasted only a couple of days, with manifestation of symptoms from stage III. There was only a two-month-gap period between stages I to III. Progression through these stages is variable with a well recognized fulminant or acute course where the patient develops at least $66 \%$ of neurological disability in the first 3 months or dies within six months ${ }^{18}$, which was the case of our patient. In the series of Risk and Haddad ${ }^{19}$, approximately $10 \%$ of patients had such a fulminant course. In rapidly evolving SSPE, various stages of disease cannot be recognised. The exact mechanism producing an acute fulminant course is not known. Several factors such as exposure to measles at an early age, viral virulence, impaired host defense mechanisms, and concurrent infections with other viruses, have been suggested as responsible for producing a rapid course of the disease $^{7,19}$. The disease is fatal in $90-95 \%$ of cases $^{13}$.

Literature points out additional cases of SSPE with atypical features. These include age of onset, visual loss, seizures, and other focal symptoms as initial presentations, besides a lack of SSPE-specific EEG pattern. A patient could have more than one of these atypical features ${ }^{2,3,20}$. Our patient had seizures at the onset. The reasons behind the atypical presentations have not been elucidated. The interesting issue is that despite immunization that may prime a host immune response to wild type measles, the virus is still able to persist in the CNS and cause SSPE. Does the priming of the immune response to measles in this setting predispose an individual to atypical SSPE ? This issue has not been systematically studied yet.

During the early phase of the illness, the EEG may be normal or show nonspecific slowing. Our patient presented with a characteristic EEG pattern consisting of periodic generalized complexes described as stereotyped high-amplitude multiphasic discharges recurring at regular intervals of approximately 5-10 seconds and having a 1:1 relationship with myoclonic jerks. Neuroimaging procedures are not necessary for SSPE diagnosis but may help in the differential diagnosis. Our patient had a normal cranial CT scan, which was obtained in the early stage of the disease.

Although characteristic clinical and neuroimaging features are helpful in making the diagnosis of SSPE, laboratory testing is necessary for confirmation. In our patient, CSF showed pleocytosis, which is rather rare, as pointed out by Prashanth et al. ${ }^{13}$, who found it in only one of 307 Indian patients studied. In SSPE, specific measles virus antibodies are found in the CSF due to intrathecal production of antibodies as specific immune response to virus in the CNS. These specific antibodies help in the diagnosis as well as in the follow-up of patients on treatment, as a tool to assess improvement ${ }^{13}$.

The pharmacologic management of SSPE can be divided into disease modifying agents and symptomatic therapies. The latter are largely directed at seizure control and all the evidence is empirically based $^{20}$. Our patient was resistant to the empirical treatment proposed, having had only a partial recovery, which might be attributable to the natural progression of the disease as shown in stage III.

Although no treatment has proven effective, oral isoprinosine and intrathecal administration of $\alpha$-interferon may prolong survival. Many different regimens of antiviral and immunomodulating therapy in SSPE have been described, usually in small, uncontrolled case series. In the case of our 8-year-old patient, the latency of the disease was quite short and immunomodulating therapy was not initiated ${ }^{20}$. 
A diagnosis of SSPE was made based on three criteria (clinical presentation, EEG and laboratory findings), combined with the exclusion of differential diagnoses by neuroimaging and other viral CSF serologies, and the clinical course. Disease onset with seizures and the fulminant course determined the atypical presentation of our case. There was no response to antiepileptic drugs and the patient died in less than 6 months after the onset of neurological disabilities, confirming the fulminant presentation of the disease.

SSPE is often not considered because of its rarity and the nonspecific clinical manifestations at onset. It is a major source of morbidity and mortality in many regions of the developing world and therefore should not be forgotten. As the disorder can mimic an insidious and acute encephalopathy, it should be included in the differential diagnosis of encephalitis mainly in the youth. The pathogenesis of this disorder remains elusive and treating it continues to be a dauting task. This report should serve to disseminate among physicians the possibility of SSPE arising in the context of normal exposures to measles virus and particularly to measles immunization. Awareness of the possibility that the clinical presentation of SSPE may be changing may increase its timely diagnosis.

Aknowledgment - We are indebted to Ricardo Rocha Bastos and Paulo Sérgio Gonçalves da Costa for their critical review of the manuscript and many helpful suggestions.

\section{REFERENCES}

1. Dyken PR. Subacute sclerosing panencephalitis: current status. Neurol Clin 1985;3:179-196.
2. Honarmand S, Glaser CA, Chow E, et al. Subacute sclerosing panencephalitis in the differential diagnosis of encephalitis. Neurology 2004; 63:1489-1493.

3. Gascon GG. Subacute sclerosing panencephalitis. Semin Pediatr Neurol 1996;3:260-269.

4. Nunes ML, Da Costa JC, Stancher VM, et al. Subacute sclerosing panencephalitis: clinical aspects and prognosis. The Brazilian registry. Arq Neuropsiquiatr 1999;57:176-181.

5. Garg RK, Karak B, Sharma AM. Subacute sclerosing panencephalitis. Indian Pediatr 1998;35:337-344.

6. Jabbour JT, Duenas DA, Modlin J. Subacute sclerosing panencephalitis: clinical staging, course and frequency. Arch Neurol 1975;32:493.

7. Campbell C, Levin S, Humphreys P, Walop W, Brannan R. Subacute sclerosing panencephalitis: results of the Canadian Paediatric Surveillance Program and review of the literature. BMC Pediatrics 2005;5:47.

8. Salehi HR, Delgado E, Wolf SM, McGoldrick PE, Moshé SL. Subacute sclerosing panencephalitis with atypical features. Pediatr Neurol 2005; 33:280-282.

9. Dunn RA. Subacute sclerosing panencephalitis. Pediatr Infect Dis J 1991; 10:68-72.

10. Garg RK. Subacute sclerosing panencephalitis. Postgrad Med J 2002; 78:63-70.

11. Quadros CA, Olive JM, Hersh BS, et al. Measles elimination in the Americas: evolving strategies. J Am Med Assoc 1996;275:224-229.

12. Bellini WJ, Rota JS, Lowe LE, et al. Subacute sclerosing panencephalitis: more cases of this disease are prevented by measles immunization than was previously recognized. J Infect Dis 2005;192:1686-1693.

13. Prashanth LK, Taly AB, Ravi V, Sinha S, Rao S. Long term survival in subacute sclerosing panencephalitis: an enigma. Brain Dev 2006;28:447-452.

14. Miller C, Andrews N, Rush M, MunroH, Jin L, Miller E. The epidemiology of subacute sclerosing panencephalitis in England and Wales 19902002. Arch Dis Child 2004;89:1145-1148.

15. Bojinovaa VS, Dimovaa PS, Belopitovaa LD, et al. Clinical and epidemiological characteristics of subacute sclerosing panencephalitis in Bulgaria during the past 25 years (1978-2002). Eur J Pediatr Neurol 2004;8:89-94.

16. Ip P, Chung BHY, Wong VCN, Chan K. Subacute sclerosing panencephalitis in children: prevalence in South China. Pediatr Neurol 2004;31:46-51.

17. Takasu T, Mgone JM, Mgone CS, et al. A continuing high incidence of subacute sclerosing panaencephalitis (SSPE) in the Eastern Highlands of Papua New Guinea. Epidemiol Infect 2003;131:887-898.

18. Grippo J, Caceres L, Assis A, Grippo T, Ruprecht B, Lopez M. Panencefalitis esclerosante subaguda: forma fulminante. Rev Neurol 2003;36:536-539.

19. Risk WS, Haddad FS. The variable natural history of subacute sclerosing panencephalitis: a study of 118 cases from the Middle East. Arch Neurol 1979;56:610-614.

20. Gascon G, Yamani S, Crowell J, et al. Combined oral isoprinosine-intraventricular $\alpha$-interferon therapy for subacute sclerosing panencephalitis. Brain Dev 1993;15:346-355. 